\title{
Analysis of left ventricular diastolic function
}

\author{
Kazuhiro Yamamoto, Margaret M Redfield, Rick A Nishimura
}

Left ventricular diastolic function is a broad term which refers to a group of complex processes which interact to determine the resistance to filling of the left ventricle. ${ }^{1}$ Impairment in one or more of these processes may increase the resistance to filling and result in the need for raised filling pressures to maintain filling and cardiac output. Because of its complex and multifactorial nature "diastolic function" is difficult to assess in patients. Doppler echocardiography has emerged as a powerful non-invasive tool to assess the characteristics of left ventricular filling, producing insight into diastolic function and its effect on filling pressures. This section will review the multiple interrelated factors which affect diastolic function and how Doppler echocardiography can be used to assess diastolic filling of the left ventricle. The interpretation of the various Doppler filling velocity curves as well as the practical utility of Doppler in the assessment of filling pressures and prognosis will be discussed.

\section{Components of diastolic function}

Diastolic function of the left ventricle is dependent upon a sequence of multiple interrelated events. For simplistic purposes, diastole can be divided into two phases ${ }^{2}$ : (1) the isovolumic relaxation phase (composed of rapid left ventricular pressure fall due to relaxation and elastic recoil) and (2) the filling phase (composed of continuing relaxation and elastic recoil, myocardial stiffness, ventricular interaction, and pericardial restraint) which can be further divided into the process of early rapid filling, the period of diastasis, and the period of atrial systole. $^{2}$ Relaxation is an energy-requiring active process whereby calcium ions are removed from the cytoplasm against a concentration gradient allowing dissociation of the contractile complex. ${ }^{3}$ Relaxation is mainly determined by cellular inactivation, loading conditions, and non-uniformity in the ventricle. The rate of relaxation determines the rate of left ventricular pressure fall during the isovolumic relaxation period characterised by the time constant of isovolumic left ventricular pressure fall (Tau). ${ }^{45}$ The impaired rate of relaxation slows the rate of left ventricular pressure fall and prolongs Tau. An extent of relaxation determines the myocardium's equilibrium length and thus left ventricular equilibrium volume. Incomplete relaxation results in a smaller left ventricular volume at a given left ventricular pressure and thus an increase of filling pressure is required to maintain left ventricular diastolic volume. At end systole the myocardium is compressed shorter than its equilibrium length and elastic energy is stored in the myocardium. The stored energy which is released as relaxation starts contributes to left ventricular pressure fall and is referred to as elastic recoil or "suction". Depressed systolic function results in increased left ventricular end systolic volume and impaired elastic recoil.

Left ventricular compliance is a passive function which indicates the distensibility of the chamber during filling of the left ventricle. As left ventricular compliance decreases, the slope of the left ventricular diastolic pressurevolume curve becomes steeper and there is a larger increase in diastolic pressure with any given filling volume. Left ventricular compliance is primarily determined by myocardial characteristics and load. Myocardial characteristics are altered in the presence of myocardial hypertrophy, ischaemia, fibrosis, or infiltration (that is, amyloid). Because the diastolic pressure-volume relation for any ventricle shows concave curvilinearity, ${ }^{1}$ left ventricular "operant" compliance can be decreased as ventricular volume is increased even without changes in myocardial characteristics. Other variables which influence left ventricular compliance are ventricular interaction, pericardial restraint, and coronary vascular engorgement. ${ }^{1}$ The cardiac chambers mechanically interact with each other and increases in right ventricular diastolic volume augment interventricular interaction and shift the left ventricular diastolic pressure-volume curve upwards. Pericardial restraint also shifts the diastolic pressurevolume curve upwards, and thus left ventricular diastolic pressure is increased at a given ventricular volume. An increase in coronary artery tugor reduces left ventricular compliance.

\section{Clinical significance of diastolic \\ dysfunction}

Recognition of the clinical significance of left ventricular diastolic dysfunction has emerged in the past 10 years. Impairment of diastolic function precedes systolic dysfunction in the progression of most cardiac diseases. ${ }^{67}$ Several studies have reported that $30-40 \%$ of patients with clinical symptoms of congestive heart failure have normal systolic function ${ }^{8-10}$ and isolated diastolic dysfunction as a cause of heart failure is now well recognised. Furthermore, even in the presence of systolic dysfunction, the clinical symptoms of heart failure are influenced primarily by the degree of diastolic dysfunction. ${ }^{11-13}$ In patients with pure "diastolic heart failure" the therapeutic strategy may be 
Pressure tracings

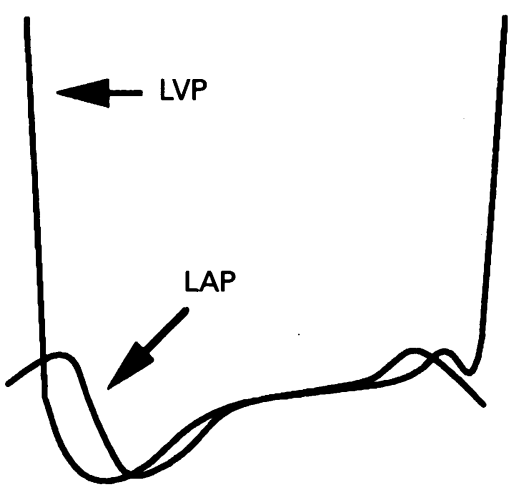

Mitral flow

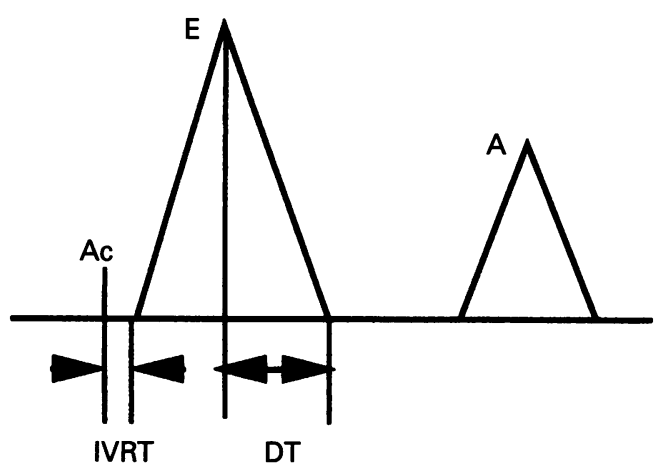

PV flow

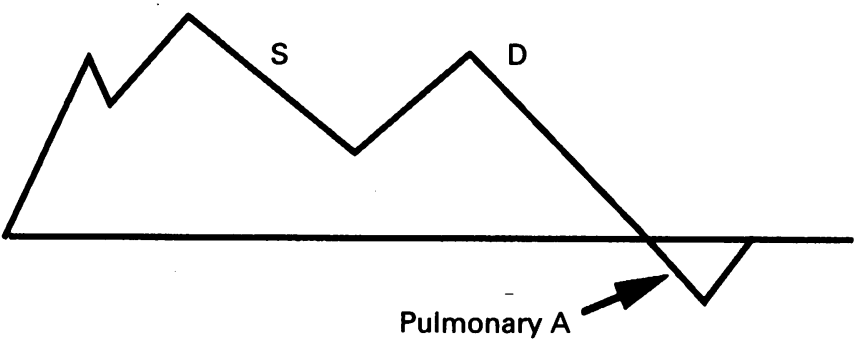

ECG

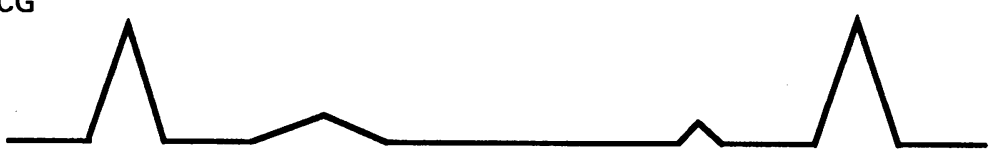

Figure 1 Left atrial and left ventricular pressure tracings ( $L A P, L V P$ ), transmitral flow velocity curves (mitral flow), and pulmonary venous flow velocity curves (PV flow).

Abbreviations: $A=$ flow velocity curve at atrial contraction (mitral $A$ velocity curve); $A c$ $=$ aortic valve closure; $D=$ pulmonary venous diastolic flow velocity curve; $D T=$ deceleration time of mitral $E$ velocity curve; $E=$ early diastolic flow velocity curve (mitral $E$ velocity curve); $E C G=$ electrocardiogram; $I V R T=$ isovolumic relaxation time; pulmonary $A=$ reversal of pulmonary venous flow velocity curve at atrial contraction; $S$ $=$ pulmonary venous systolic flow velocity curve.

different from that in patients with "systolic heart failure". ${ }^{14}$ Though the concept of diastolic heart failure is acknowledged, it remains difficult to establish this diagnosis clinically. Thus a non-invasive method to assess diastolic function and filling pressures is needed.

\section{Assessment of left ventricular diastolic filling by digitised $M$ mode echocardiography}

The digitisation of the standard $M$ mode echocardiogram of the left ventricle enables a continuous measure of left ventricular dimension throughout the cardiac cycle. This provides information regarding ventricular diastolic filling and is useful in characterising the diastolic properties of patients with cardiac disease. ${ }^{15}$ For example, it has been shown that patients with ventricular hypertrophy have a reduced rate of increase in left ventricular diameter during the rapid filling phase. ${ }^{16}$ It is proposed that the evaluation of left ventricular diastolic filling flow velocities may provide additional information to the assessment of left ventricular diastolic function as compared with the evaluation of the volume changes of the left ventricle alone, and that these velocities can be easily assessed by Doppler echocardiography.

Assessment of left ventricular diastolic filling by Doppler echocardiography: determinants of transmitral and pulmonary venous flow velocity curves

The advent of Doppler echocardiography has resulted in a method by which velocities in cardiac chambers and across valves can be measured non-invasively and easily. It has been proposed that analysis of transmitral and pulmonary venous flow velocity curves offers a non-invasive approach for an indirect measure of left ventricular diastolic function. It is important to understand that Doppler velocity curves assess filling of the left ventricle and do not directly examine the complexities of the total diastolic function of the heart (fig 1).

TRANSMITRAL FLOW VELOCITY CURVE

The transmitral flow velocity curves obtained from pulsed wave Doppler reflect blood flow from the left atrium to the left ventricle during the diastolic filling period. When the sample volume is placed at the level of mitral annulus, there is a biphasic contour consisting of an early diastolic flow velocity curve (mitral E) and a flow velocity curve at atrial contraction (mitral A), which have been confirmed to correspond to the first derivative of left ventricular diastolic volume recordings-that is, volumetric flow rate. ${ }^{17}$ Placement of the sample volume at the tips of the mitral valve leaflets will record the highest velocities, which are determined by the left atrial to left ventricular pressure gradient during diastole. ${ }^{18} 19$ These velocities are used to evaluate diastolic filling of the left ventricle because they reflect the driving pressure across the mitral valve. Transmitral Doppler variables routinely assessed include mitral $\mathrm{E}$ velocity, deceleration time of mitral $E$ velocity curve, mitral A velocity, and mitral A duration.

When left ventricular pressure falls below left atrial pressure owing to ventricular relaxation, there is a driving pressure across the mitral valve which accelerates the velocity of the flow and causes the mitral $E$ velocity. Left atrial pressure with continuing left ventricular relaxation and elastic recoil produces the transmitral pressure gradient. During early diastolic filling, left atrial pressure falls, the rate of fall being determined by the emptying volume and left atrial compliance. These determinants of the positive pressure gradient determine the peak mitral $\mathrm{E}$ velocity. As early diastolic filling continues, left ventricular pressure starts to increase after reaching its nadir due to viscoelastic forces of the myocardium, passive 
Haemodynamic factors affecting transmitral and pulmonary venous flow velocity curves

\begin{tabular}{|c|c|c|}
\hline & $L A$ factors & $L V$ factors \\
\hline \multicolumn{3}{|c|}{ Transmitral flow velocity curves } \\
\hline Mitral E velocity curve & $\begin{array}{l}\text { LA pressure } \\
\text { LA compliance }\end{array}$ & $\begin{array}{l}\text { LV relaxation, elastic recoil (LV contractility) } \\
\text { LV compliance, interventricular interaction, } \\
\text { myocardial viscoelasticity }\end{array}$ \\
\hline Mitral A velocity curve & $\begin{array}{l}\text { LA pressure (preload for atrial } \\
\text { contraction) } \\
\text { LA contractility } \\
\text { PR interval }\end{array}$ & $\begin{array}{l}\text { LV compliance, pericardial restraint, } \\
\text { interventricular interaction, coronary } \\
\text { vascular engorgement, myocardial viscoelasticity }\end{array}$ \\
\hline \multicolumn{3}{|c|}{ Pulmonary venous flow velocity curve } \\
\hline $\begin{array}{l}\text { Pulmonary venous systolic } \\
\text { flow velocity curve }\end{array}$ & $\begin{array}{l}\text { LA contractility } \\
\text { LA relaxation } \\
\text { LA pressure } \\
\text { LA compliance }\end{array}$ & LV contractility (mitral annular motion) \\
\hline $\begin{array}{l}\text { Pulmonary venous diastolic } \\
\text { flow velocity curve }\end{array}$ & $\begin{array}{l}\text { LA pressure } \\
\text { LA compliance }\end{array}$ & $\begin{array}{l}\text { LV relaxation, elastic recoil (LV contractility), } \\
\text { LV compliance, interventricular interaction, } \\
\text { myocardial viscoelasticity }\end{array}$ \\
\hline $\begin{array}{l}\text { Pulmonary venous A velocity } \\
\text { curve }\end{array}$ & $\begin{array}{l}\text { LA pressure (preload for atrial contraction) } \\
\text { LA contractility } \\
\text { LA compliance } \\
\text { PR interval }\end{array}$ & $\begin{array}{l}\text { LV compliance (including wave reflection), } \\
\text { pericardial restraint, interventricular interaction, } \\
\text { coronary vascular engorgement, myocardial } \\
\text { viscoelasticity }\end{array}$ \\
\hline
\end{tabular}

LA = left atrial; $L V=$ left ventricular.

compliance, pericardial restraint, and ventricular interaction. The left atrial to left ventricular pressure gradient decreases and eventually left ventricular pressure exceeds left atrial pressure. The rate at which the pressure gradient is reversed determines the deceleration rate and deceleration time of mitral $\mathrm{E}$ velocity curve. ${ }^{19}$ The quicker the left ventricular pressure increases, the shorter the deceleration time is. The deceleration time has been shown to be related to the "operant" left ventricular compliance. ${ }^{20} \mathrm{With}$ atrial contraction, left atrial pressure rises and increases the transmitral pressure gradient producing the mitral A velocity curve. Increased left atrial preload enhances atrial contraction and increases the peak mitral $A$ velocity. ${ }^{21}$ The filling of the left ventricle with atrial contraction raises left ventricular pressure, which contributes to the decrease in the pressure gradient. Thus the pressure gradient at atrial contraction phase and therefore peak mitral A velocity ${ }^{19}$ is determined by left atrial systolic function, atrial preload, and left ventricular compliance (table).

Isovolumic relaxation time (the time from the aortic valve closure to mitral valve opening) can be measured as the time interval between the first high-frequency component of the second heart sound on a phonocardiogram and the onset of mitral $\mathrm{E}$ velocity by pulsed wave Doppler. Alternatively, the interval between aortic valve closure signal and mitral valve opening signal on a continuous wave Doppler signal intersecting left ventricular outflow velocity and the mitral valve motion ${ }^{22}$ or the interval between the first high-frequency component of the second heart sound on a phonocardiogram and the initial cusp separation on the mitral valve $M$ mode echocardiogram ${ }^{23}$ can be used, although the measured values are slightly different among the methods. The isovolumic relaxation time is an indirect measure of the rate of left ventricular relaxation as well as the pressure at mitral valve opening.

PULMONARY VENOUS FLOW VELOCITY CURVE Pulmonary venous flow velocity curves can be obtained from transoesophageal or transthoracic echocardiography by placing a sample volume $1-2 \mathrm{~cm}$ proximal to the junction of the pulmonary vein and the left atrium. The normal velocity curves consist of systolic and diastolic forward flow and reversed flow at atrial contraction (fig 1). Systolic forward flow (left atrial filling during ventricular contraction) is determined by left atrial relaxation, elastic recoil after atrial contraction, atrial compliance, and the downward mitral annular motion associated with ventricular contraction. ${ }^{24-26}$ Atrial relaxation affects early systolic flow while the mitral annular displacement affects late systolic flow. Thus the systolic flow velocity curve can be biphasic, especially at low left ventricular filling pressures. A decrease in systolic forward flow is seen in patients with loss of atrial contraction and relaxation, with high left atrial pressures (that is, decreased left atrial compliance) or with left ventricular systolic dysfunction (that is, decreased annular descent). Moderate or severe mitral regurgitation attenuates or reverses the systolic flow velocity curve. ${ }^{27}$

Diastolic forward flow (left atrial filling during early diastolic ventricular filling) largely reflects mitral $\mathrm{E}$ velocity curve $\mathrm{e}^{2829}$ as the left atrium serves as a conduit during this phase. Thus determinants of the mitral $E$ velocity curve are the main determinants of the pulmonary venous diastolic flow velocity curve. With atrial contraction, blood is ejected forward into the left ventricle and retrogradely into the pulmonary veins, and reversed flow is observed in the pulmonary venous flow velocity curve (pulmonary venous A). The distribution of ejected blood depends on left atrial afterload. 22430 Thus determinants of the mitral A velocity curve affect the pulmonary venous $A$ velocity curve. Furthermore, the pulmonary venous $A$ velocity curve is affected by wave reflection related to left ventricular and left atrial compliance ${ }^{31} 32$ (table).

\section{Assessment of left ventricular diastolic filling by Doppler echocardiography: influence of loading conditions}

Transmitral flow velocity curves are sensitive to preload and afterload. 1819223033 An acute decrease in left atrial pressure reduces the transmitral pressure gradient in early diastole 
A
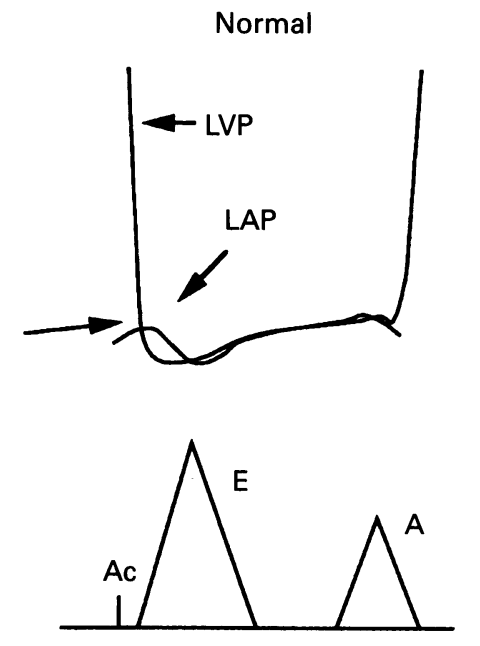

B

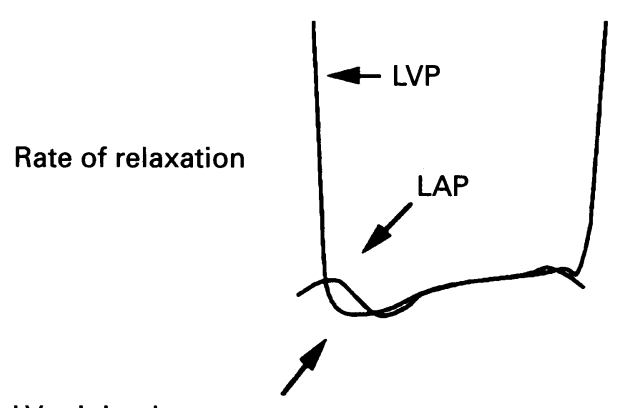

LV minimal pressure

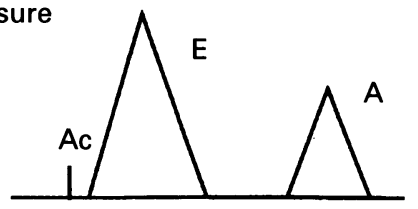

Preload reduction
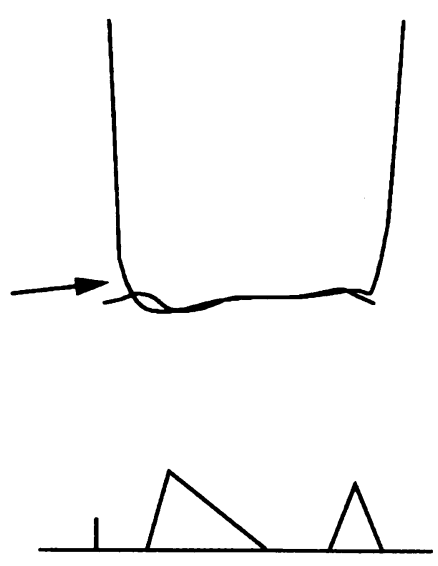

Afterload enhancement
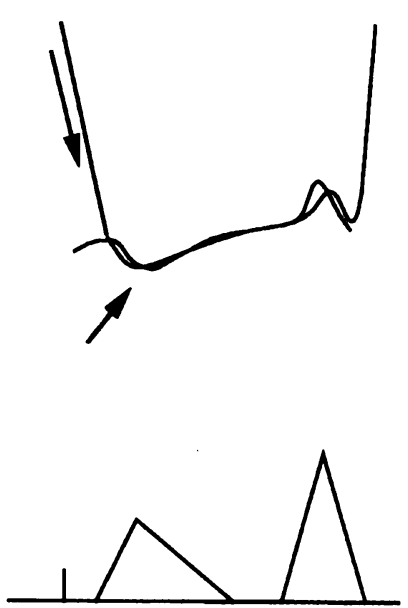

Preload enhancement
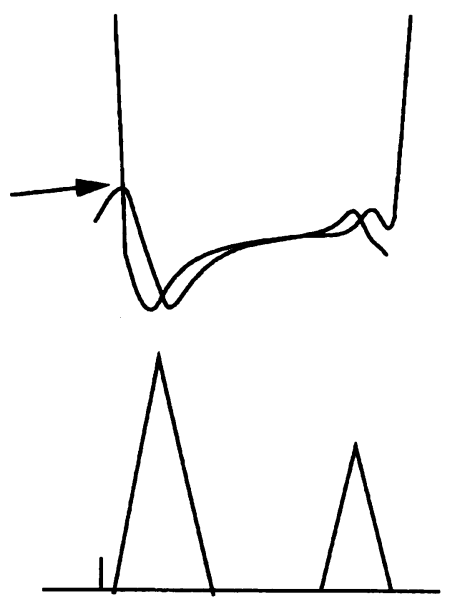

Figure 2 Left atrial and left ventricular pressure tracings (LAP, LVP) and transmitral flow velocity curves illustrating alterations of pressure tracings and flow velocity curves associated with preload $(A)$ or afterload changes $(B)$. An acute decrease in preload is associated with smaller transmitral pressure gradient in early diastole, and the mitral $E$ velocity is decreased in association with prolonged deceleration time and decreased mitral $A$ velocity. The opposite effects occur with preload augmentation. An acute increase in afterload is associated with increased left ventricular end systolic volume (impaired elastic recoil and increase in left ventricular minimal pressure), a slowed rate of left ventricular relaxation, and increased preload. Thus if an increase in preload is not great, the mitral $E$ velocity is decreased because of impaired relaxation and elastic recoil. The mitral $A$ velocity is increased because of increased preload. See legend to fig 1 for abbreviations. with a subsequent drop in mitral $\mathrm{E}$ velocity. The resultant reduction in early diastolic filling is associated with a slower increase in left ventricular pressure which prolongs the mitral deceleration time. A decreased preload for atrial contraction reduces the mitral A velocity (fig 2). Conversely, an increase in left atrial pressure will increase the transmitral pressure gradient in early diastole with a subsequent increase in mitral $\mathrm{E}$ velocity. Owing to the curvilinear nature of the diastolic pressure-volume curve, there will then be a more rapid rise in left ventricular pressure which shortens the mitral deceleration time.

An acute increase in afterload is associated with increased left ventricular end systolic volume (impaired elastic recoil), a slowed rate of left ventricular relaxation (when afterload is increased in the early ejection phase), and increased preload. ${ }^{33}$ Early diastolic filling and subsequently the mitral $E$ velocity are decreased owing to impaired relaxation and elastic recoil. With left ventricular relaxation continuing into mid or even late diastole, left ventricular filling continues to be impaired and the mitral deceleration time is prolonged. Mitral A velocity is increased by increased atrial preload at the time of atrial contraction.

The description in this section is based on a simplistic model: the transmitral flow velocity curves depend on many other interrelated factors. However, these observations and explanations do provide a conceptual framework for the interrelation of the various transmitral flow velocity curves seen in clinical studies.

\section{Assessment of left ventricular diastolic filling by Doppler echocardiography: normal and abnormal filling patterns} NORMAL TRANSMITRAL FLOW VELOCITY CURVES Several different types of filling patterns have been seen in various disease states. These velocity curves are related to many factors such as systolic function, heart rate, and age. . $^{35-39}$ With aging, the mitral $E$ velocity decreases, the mitral A velocity increases, and the mitral deceleration time and the isovolumic relaxation time are prolonged. ${ }^{36} 37$ With an increase in heart rate, the mitral A velocity is increased. ${ }^{35}$ The loading conditions of the left ventricle also affect these values as has been discussed above. However, in healthy middle aged subjects, the transmitral flow velocity curve consists of an $\mathrm{E}$ velocity slightly higher than the A velocity with a deceleration time between 180 and $240 \mathrm{~ms}$ and an isovolumic relaxation time between 80 and $110 \mathrm{~ms}$. A normal pulmonary venous flow 
Normal

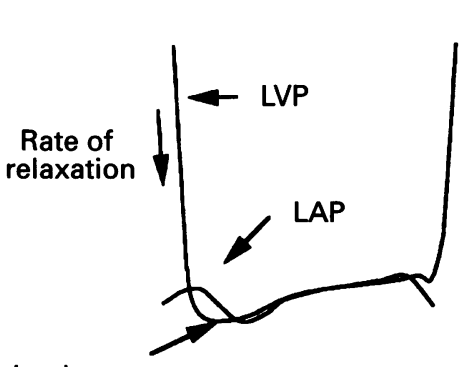

LV minimal pressure

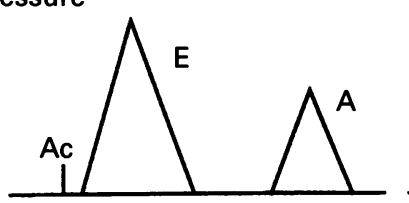

Abnormal relaxation and systolic dysfunction

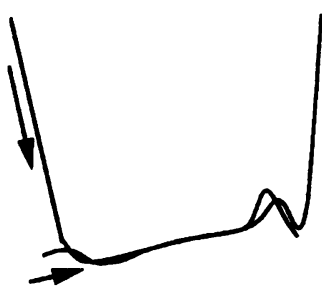

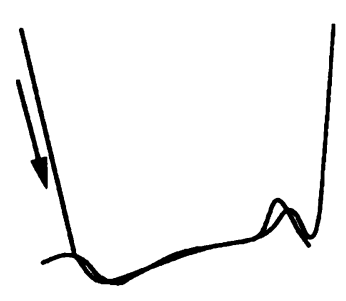

Figure 3 Left atrial and left ventricular pressure tracings ( $L A P, L V P)$ and transmitral flow velocity curves illustrating alterations in pressure tracings and flow velocity curves associated with relaxation abnormality, systolic dysfunction, and increased filling pressure. Relaxation abnormality slows the rate of relaxation with decreases in early diastolic transmitral pressure gradient and peak mitral $E$ velocity and prolongation of isovolumic relaxation time. In such patients, the deceleration time of the mitral $E$ velocity curve is unchanged or prolonged. To make up for decreased filling in the early diastolic phase, the contribution of atrial contraction is augmented by increased peak mitral $A$ velocity. Additional systolic dysfunction causes an increase in left ventricular end systolic volume and decreased elastic recoil. Left ventricular minimal pressure (small arrow) also increases and the early diastolic transmitral pressure gradient further decreases with a decrease in peak mitral $E$ velocity. If these abnormalities are associated with raised filling pressures, early diastolic transmitral pressure gradient increases with peak mitral $E$ velocity. In such patients, isovolumic relaxation time and the deceleration time of mitral $E$ velocity curve are shortened and peak mitral $A$ velocity is decreased (that is, "pseudonormalised" or restrictive pattern). See legend to fig 1 for abbreviations.

velocity curve will usually have a systolic forward flow slightly higher than the diastolic forward flow. There will be a pulmonary venous $A$ velocity of less than $0.2 \mathrm{~m} / \mathrm{s}$.

\section{ABNORMAL RELAXATION}

Using pulsed wave Doppler Kitabatake et al demonstrated that early diastolic filling is impaired and filling at atrial contraction is augmented in patients with cardiac disease. ${ }^{40}$ These findings were described as being characteristic of impaired left ventricular relaxation. ${ }^{2230}$ Abnormal relaxation induces a slow rate of left ventricular pressure fall in the early diastolic phase with a reduction in the early diastolic transmitral pressure gradient and mitral E velocity (fig 3 ). Such a slow left ventricular pressure fall prolongs the isovolumic relaxation time. A compensatory augmentation of atrial contraction increases mitral A velocity. In patients with severely impaired relaxation the effective diastolic filling period (from the onset of mitral $\mathrm{E}$ velocity to the end of mitral A velocity) is shortened and the transmitral flow velocity curve shows only single peak (summation), particularly with increased heart rate or first degree atrioventricular block. ${ }^{23}{ }^{341}$ In the pulmonary venous flow velocity curves, diastolic forward flow velocity is decreased, reflecting a decrease in mitral $\mathrm{E}$ velocity, and systolic flow velocity is increased. The pulmonary venous $A$ velocity is not enhanced in this early stage of cardiac disease if left ventricular compliance remains normal.

\section{PSEUDONORMALISATION}

As cardiac disease progresses, left ventricular compliance is reduced and left atrial pressure eventually increases. As left atrial pressure increases, the early diastolic transmitral pres- 

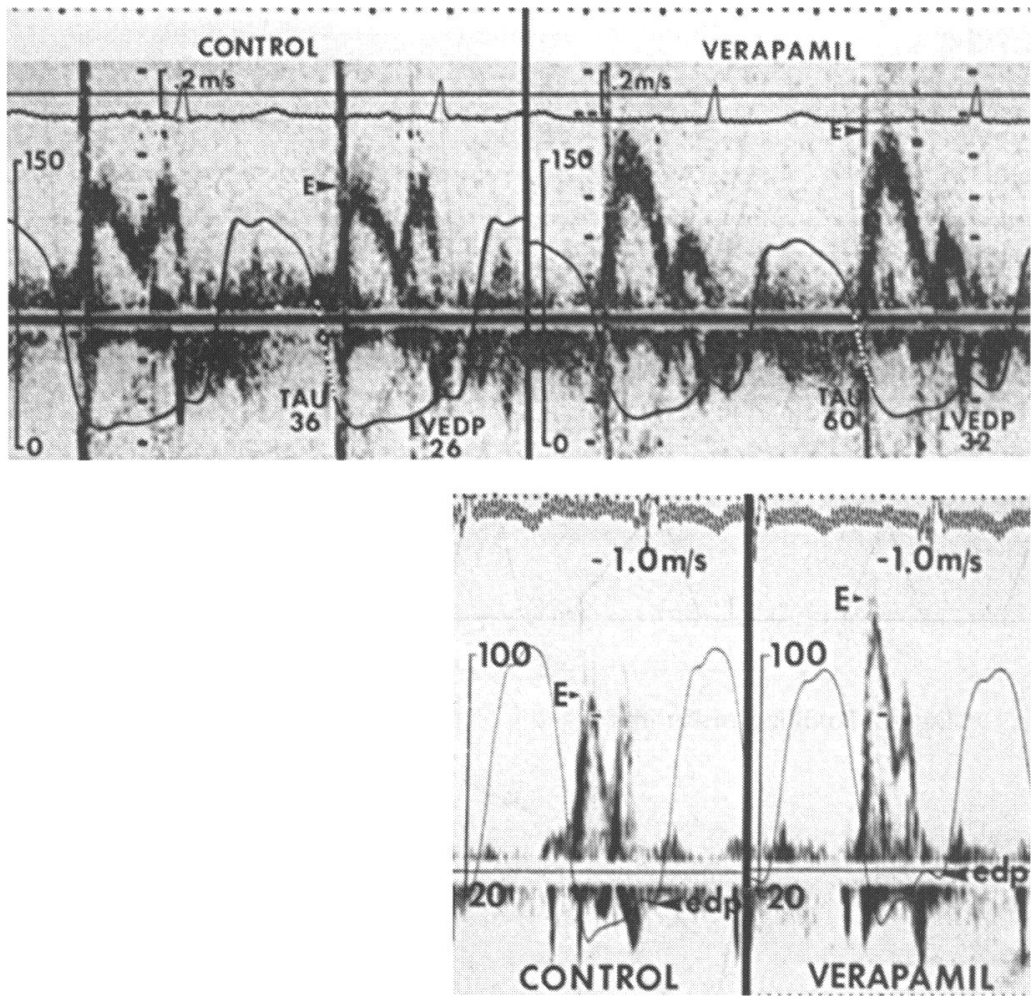

Figure 4 Simultaneous transmitral flow velocities and left ventricular pressure curves from two patients (upper and lower), before and after intravenous administration of verapamil. In patients with coronary artery disease, intravenous verapamil increases the

$E / A$ ratio ("normalises" $E / A$ ratio) but is associated with further impairment in relaxation (increased time constant of isovolumic left ventricular pressure fall (Tau)). The increase in $E / A$ ratio is caused by increases in left ventricular filling pressures - that is,

"pseudonormalisation". Abbreviations: edp = end diastolic pressure; LVEDP = left ventricular end diastolic pressure; see legend to fig 1 for other abbreviations. (Reprinted with permission from the American College of Cardiology (J Am Coll Cardiol 1993;21:182-8)). ${ }^{42}$ may be misleading ${ }^{42}$ (fig 4 ). With pseudonormalisation of mitral $\mathrm{E}$ velocity, pulmonary venous diastolic flow velocity is increased. The systolic forward flow velocity is usually decreased with increased left atrial pressure. However, the systolic forward flow velocity may not necessarily be decreased in patients with preserved ventricular systolic function. Reflecting increased resistance to left ventricular filling at atrial contraction, pulmonary venous $A$ velocity is increased and widened. ${ }^{32434}$

\section{RESTRICTION TO FILLING}

As alteration in ventricular compliance and atrial pressures progresses, the mitral $\mathrm{E}$ velocity and E/A ratio increase further with marked decreases in the deceleration time and isovolumic relaxation time. This constellation of findings is referred to as a "restrictive pattern". ${ }^{22} 30$ Usually, the $\mathrm{E} / \mathrm{A}$ ratio is more than 2.0 and the mitral deceleration time is less than $150 \mathrm{~ms}$. Pulmonary venous diastolic flow velocity and pulmonary venous A velocity increase further with a further decrease in the systolic flow velocity.

PROGRESSION OF FLOW VELOCITY CURVES AND DISEASE STATES

Based on these observations, a simplified schematic diagram illustrating the progression of these flow velocity curves in disease states has been proposed ${ }^{45}$ (fig 5). These progressive changes have been clearly demonstrated in individual patients with cardiac amyloidosis. ${ }^{46}$ The clinical significance of these curves has been verified in patients with other cardiac diseases by demonstrating that a "pseudonormal" or "restrictive" transmitral flow velocity curve indicates a poor prognosis. ${ }^{11448}$ As is evident from fig 5, patients found to have an abnormal relaxation pattern are usually minimally symptomatic in the early stage of disease progression.

Conversely, patients with a restrictive pattern are usually symptomatic in the end stage of disease progression. There can be rapid alternation between abnormal relaxation and pseudonormal patterns or between pseudonormal and explains why an assessment of diastolic fun tion with transmitral flow velocity curves alone

Figure 5 Diagram showing the hypothetical progression of changes in transmitral and pulmonary venous flow velocity curves that occur with aging and in cardiac disease with progressive diastolic dysfunction. With aging or in patients with many types of cardiac diseases that cause impairment of left ventricular relaxation, mitral $E$ velocity and pulmonary venous diastolic flow velocity (PVd) progressively decrease while isovolumic relaxation time (IVRT), the deceleration time of the mitral $E$ velocity curve, and pulmonary venous systolic flow velocity (PVs) increase. Pulmonary venous $A$ velocity (PVa) may be normal (solid line) or increased (dashed line) at this stage depending on left atrial and left ventricular compliance and left atrial systolic function. In association with a decrease in left ventricular compliance, left atrial pressure begins to increase with increases in mitral $E$ velocity, pulmonary venous diastolic flow velocity, and pulmonary venous $A$ velocity and duration and decreases in the deceleration time of mitral $E$ velocity curve, mitral $A$ velocity and duration, and pulmonary venous systolic flow velocity. At these stages, the transmitral flow velocity pattern is "pseudonormalised" and then "restrictive". (Reprinted with permission from Echocardiography 1992;9:437-57).45 


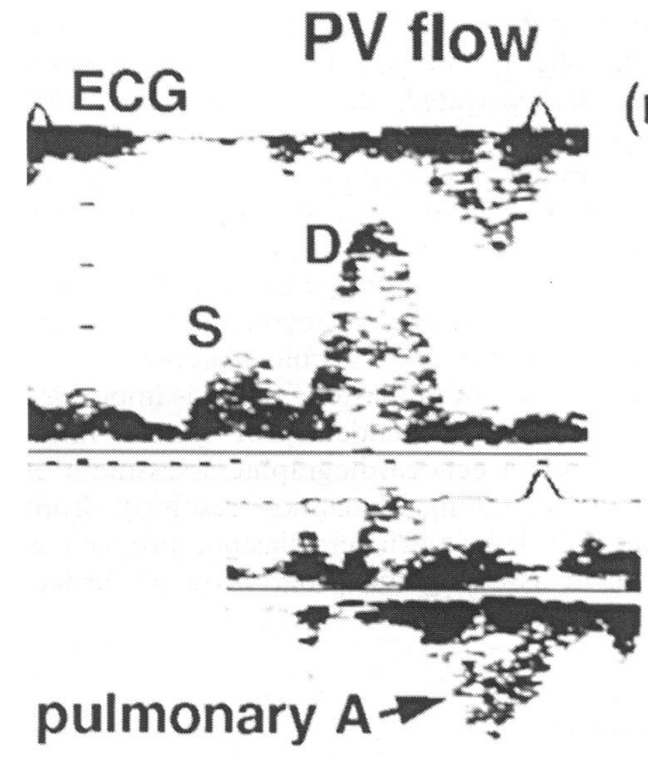

\section{Mitral flow}

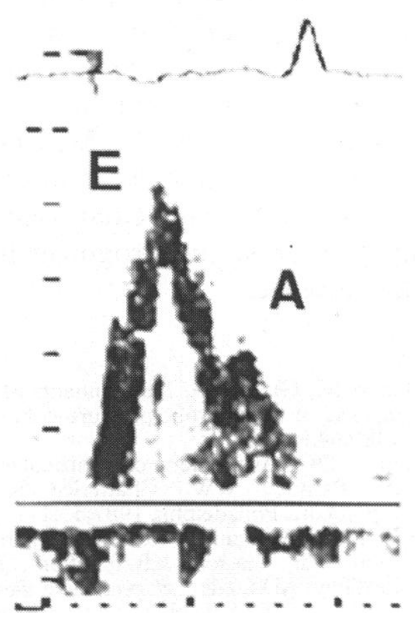

Figure 6 Pulsed Doppler pulmonary venous flow velocity curve (PV flow), transmitral flow velocity curve (mitral flow), and left ventricular pressure tracing (LVP) in a patient with an ejection fraction of $22 \%$. Raised left ventricular end diastolic pressure (LVEDP) is associated with a decrease in peak pulmonary venous systolic flow velocity and increases in peak pulmonary venous diastolic flow velocity and peak pulmonary venous $A$ velocity. In transmitral flow velocity curves, peak mitral $E$ velocity is increased, the deceleration time of mitral $E$ velocity curve is shortened, and peak mitral $A$ velocity is decreased. $A$ comparison of transmitral and pulmonary venous flow velocity curves demonstrates that the duration of the pulmonary venous $A$ velocity curve is longer than that of the mitral $A$ velocity curve and that cessation of the pulmonary venous $A$ velocity curve occurs later than that of the mitral $A$ velocity curve as determined by reference to the $R$ wave on the electrocardiogram. See legend to fig 1 for abbreviations.

early restrictive patterns in the same patient, depending on the treatment and response to therapy. However, we have not seen the abnormal relaxation pattern revert back to a normal pattern or the late stage restrictive pattern revert back to the pseudonormal pattern.

In a patient who has had serial assessment of transmitral filling velocity curves the progression of disease can usually be identified. For instance, if an initial assessment revealed an abnormal relaxation pattern, the occurrence of a "normal" velocity curve would indicate a "pseudonormal" pattern with raised filling pressures and worsening ventricular compli- ance. However, in a patient presenting for the first time with a normal transmitral flow velocity curve it is not easy to distinguish between a "pseudonormal" transmitral flow velocity curve and a "normal" curve; additional information is necessary. As fig 5 shows, in patients with a "pseudonormal" transmitral flow velocity curve, pulmonary venous A velocity is frequently enhanced. A reduction in E/A during the Valsalva manoeuvre is likely to be large in patients with a pseudonormal flow velocity curve..$^{49}$ Detecting raised pulmonary artery end diastolic pressure, an enlarged left atrium, a reduced left atrial ejection fraction, and reduced rate of left ventricular wall thinning during early diastole may be helpful..$^{4450}$ Recently new markers for quantitatively detecting diastolic dysfunction were proposed. One is to measure the intraventricular propagation of early diastolic filling flow with colour $\mathrm{M}$ mode or multigated pulsed Doppler echocardiography. ${ }^{51}{ }^{52}$ In patients with relaxation abnormality, the flow propagation is impaired independently of filling pressures. Another is to use continuous wave mitral or aortic regurgitant flow velocity curves to calculate $-\mathrm{dP} / \mathrm{dt}$ and Tau. ${ }^{53} 54$

\section{Assessment of left ventricular filling pressures}

Giannuzzi et $a l^{55}$ recently reported that the mitral deceleration time and E/A ratio correlate well with filling pressures in patients with poor systolic function. The deceleration time correlated better than the $\mathrm{E} / \mathrm{A}$ ratio. In patients with left ventricular systolic dysfunction, the transmitral flow velocity curve can be reliably used to determine left ventricular filling pressures. As mean left atrial pressure goes up, there will be a high E/A ratio and a short deceleration time. However, these indices may not necessarily correlate as well with filling pressures in a more heterogeneous population. ${ }^{44}{ }^{56}$ If there are patients with normal systolic function, a deceleration time of $200 \mathrm{~ms}$ could arise from either a normal (normal left atrial pressure) or "pseudonormal" (much increased left atrial pressure) transmitral flow velocity curve and the transmitral flow velocities may not reflect filling pressures (figs 6 and 7).

Pulmonary venous flow velocity curves can be used as an adjunct to transmitral flow velocity curves to assess filling pressures. With an increase in filling pressures, pulmonary venous systolic fraction (a ratio of the time-velocity integral of the systolic forward flow velocity curve to the time-velocity integrals of the systolic and diastolic forward flow velocity curves) and the ratio of peak systolic to peak diastolic forward flow velocities decrease and peak diastolic flow velocity and peak pulmonary venous A velocity increase. ${ }^{435758}$ Although generally a low systolic fraction reflects a high filling pressure, pulmonary venous flow velocity curves are also affected by many other variables. ${ }^{24-27} 29$ Thus a patient with hyperdynamic systolic function which causes rapid descent of the annulus may maintain a high systolic fraction despite a high filling pressure.

Recent studies have reported the utility of 


\section{ECG PV flow}
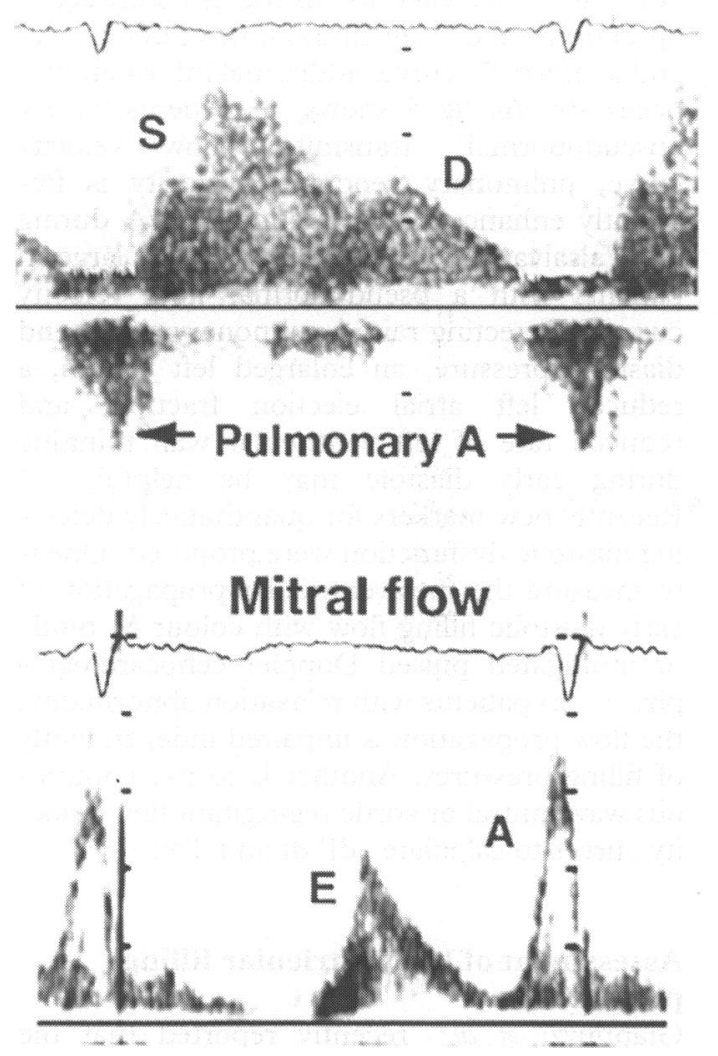

Figure 7 Pulsed Doppler pulmonary venous flow velocity curve (PV flow), transmitral flow velocity curve (mitral flow), and left ventricular pressure tracing (LVP) in a patient with an ejection fraction of $70 \%$. Although left ventricular end diastolic pressure (LVEDP) is increased, peak pulmonary venous systolic flow velocity is higher than peak pulmonary venous diastolic flow velocity, and peak mitral $E$ velocity is lower than peak mitral $A$ velocity. The deceleration time of the mitral $E$ velocity curve is not shortened. However, peak pulmonary venous $A$ velocity is increased, the duration of the pulmonary. venous $A$ velocity curve is longer than that of the mitral $A$ velocity curve, and the cessation of the pulmonary venous $A$ velocity curve occurs later than that of the mitral $A$ velocity curve as determined by reference to the $R$ wave. See legend to fig 1 for abbreviations.

the combined analysis of transmitral and pulmonary venous flow velocity curves in assessing filling pressures..$^{324}$ Matsuda et al ${ }^{31}$ demonstrated that the left atrial pressure wave with atrial contraction increased in magnitude and duration as left ventricular diastolic pressures increased and the prolongation of the left atrial pressure wave at atrial contraction was thought to be due to increased wave reflection from a non-compliant left ventricle. Based on this observation they postulated that such changes in atrial pressure would prolong pulmonary venous $\mathrm{A}$ duration and they showed that the duration of the pulmonary venous $A$ velocity curve exceeded that of the mitral A velocity curve in patients with raised filling pressures and that the difference in the durations correlates well with filling pressures. ${ }^{32}{ }^{44}$ In our preliminary data the relation between the difference in the durations and filling pressures was less affected by left ventricular systolic function than by other indices derived from transmitral or pulmonary venous flow velocity curves $^{59}$ (figs 6 and 7).

\section{Prognosis}

Though care must be taken in the interpretation of transmitral and pulmonary venous flow velocity curves, they can reflect the progression of diastolic dysfunction. Recent clinical studies have demonstrated that an increased $\mathrm{E} / \mathrm{A}$ $(>2 \cdot 0)$ and/or a shortened deceleration time of the mitral $\mathrm{E}$ velocity curve ( $<150 \mathrm{~ms})$ - that is, a restrictive pattern-is a strong marker of the progression of cardiac diseases and of poor prognosis in patients with dilated cardiomyopathy, amyloidosis, and old myocardial infarction independently of their systolic function. ${ }^{1145-4860}$ Thus assessment of diastolic filling is important for prognosis independently of systolic function. Doppler echocardiographic assessment of changes in filling dynamics resulting from changes in left ventricular diastolic property is useful in assessing the progression of cardiac diseases $^{45} 61$ (fig 5).

\section{Summary}

Our understanding of left ventricular diastolic function has evolved with our understanding of Doppler echocardiographic assessment of left ventricular filling dynamics. Left ventricular diastolic function consists of several variables which affect the Doppler echocardiographic recordings in a complex way. While there are still limitations with the non-invasive assessment of left ventricular diastolic function and filling pressures by Doppler echocardiography, great progress has been made and careful interpretation of properly obtained Doppler recordings can give clinically relevant information concerning left ventricular diastolic function, filling pressures, and prognosis in patients with cardiac disease.

1 Gilbert JC, Glantz SA. Determinants of left ventricular filling and of the diastolic pressure-volume relation. Circ Res ing and of the diast

2 Gibson DG. Assessment of ventricular diastolic function. In: Parmley WW, Chatteriee $\mathrm{K}$, eds. Cardiology. Lippincott: Philadelphia 1987;53:1-17.

3 Apstein CS, Morgan JP. Cellular mechanisms underlying left ventricular diastolic dysfunction. In: Gaasch WH, LeWinter MM, eds. Left ventricular diastolic dysfunction and heart failure, Philadelphia: Lea and Febiger, 1994;3-24.

4 Raff GL, Glantz SA. Volume loading slows left ventricular isovolumic relaxation rate: evidence of load-dependent relaxation in the intact dog heart. Circ Res 1981;48 813-24.

5 Weiss JL, Frederiksen JW, Weisfeldt ML. Hemodynamic determinants of the time-course of fall in canine left ventricular pressure. $\mathcal{F}$ Clin Invest 1976;58:751-60.

6 Hirota Y. A clinical study of left ventricular relaxation. Circulation 1980;62:756-63.

7 Rousseau MF, Veriter C, Detry JMR, Brasseur L, Pouleur H. Impaired early left ventricular relaxation in coronary artery disease: effects of intracoronary nifedipine. Circulation 1980;62:764-72.

8 Dougherty AH, Naccarelli GV, Gray EL, Hicks CH, Goldstein RA. Congestive heart failure with normal systolic function. Am $\mathcal{F}$ Cardiol 1984;54:778-82.

9 Soufer R, Wohlgelernter D, Vita NA, Amuchestegui M, Soufer R, Wohlgelernter D, Vita NA, Amuchestegui M,
Sostman HD, Berger HJ, et al. Intact systolic left ventricuSostman $\mathrm{HD}$, Berger $\mathrm{HJ}$, et al. Intact systolic left ventricu-
lar function in clinical congestive heart failure. $A m \mathcal{F}$ lar function in clinical

10 Aguirre FV, Pearson AC, Lewen MK, McCluskey M, Aguirre FV, Pearson AC, Lewen MK, McCluskey M,
Labovitz AJ. Usefulness of Doppler echocardiography in Labovitz AJ. Usefulness of Doppler echocardiography in
the diagnosis of congestive heart failure. Am $尹$ Cardiol the diagnosis of cong

11 Vanoverschelde JL, Raphael DA, Robert AR, Cosyns JR Left ventricular filling in dilated cardiomyopathy: relation to functional class and hemodynamics. $\mathcal{f} \mathrm{Am}$ Coll Cardio 1990;15:1288-95.

12 Packer M. Abnormalities of diastolic function as a potential cause of exercise intolerance in chronic heart failure.

13 Sobue $T$, Yokota $M$, Iwase $M$, Ishihara $H$. Influence of left ventricular hypertrophy on left ventricular function during dynamic exercise in the presence or absence of coronary artery disease. F Am Coll Cardiol 1995;25:91-8.

14 Bonow RO, Udelson JE. Left ventricular diastolic dysfunction as a cause of congestive heart failure. Ann Intern Med 1992;117:502-10. 
15 Upton MT, Gibson DG. The study of left ventricular function from digitized echocardiograms. Prog Cardiovasc Dis 1978;20:359-84.

16 Hanrath P, Mathey DG, Siegert R, Bleifeld W. Left ventricular relaxation and filling pattern in different forms of left ventricular hypertrophy: an echocardiographic study. $A m \mathcal{F}$ Cardiol 1980;45:15-23.

17 Rokey R, Kuo LC, Zoghbi WA, Limacher MC, Quinones MA. Determination of parameters of left ventricular diastolic filling with pulsed Doppler echocardiography: comtolic filling with pulsed Doppler echocardiography: com-
parison with cineangiography. Circulation 1985;71: parison

18 Ishida Y, Meisner JS, Tsujioka K, Gallo JI, Yoran C, Frater RWM, et al. Left ventricular filling dynamics: influence of $\mathrm{RWM}, e t$ al. Left ventricular filling dynamics: influence of
left ventricular relaxation and left atrial pressure. left ventricular relaxation
Circulation 1986;74:187-96.

19 Courtois M, Vered Z, Barzilai B, Ricciotti NA, Perez JE, Ludbrook PA. The transmitral pressure-flow velocity relation: effect of

20 Ohno M, Cheng CP, Little WC. Mechanism of altered patterns of left ventricular filling during the development of congestive heart failure. Circulation 1994;89:2241-50.

21 Choong CY, Abascal VM, Thomas JD, Guerrero $\mathrm{J}$, McGlew S, Weyman AE. Combined influence of ventricular loading and relaxation on the transmitral flow velocity profile in dogs measured by Doppler echocardiography. Circulation 1988;78:672-83.

22 Nishimura RA, Abel MD, Hatle LK, Tajik AJ. Assessment of diastolic function of the heart: background and current applications of Doppler echocardiography. Part II. Clinical studies. Mayo Clin Proc 1989;64:181-204.

$23 \mathrm{Ng} \mathrm{KSK}$, Gibson DG. Impairment of diastolic function by shortened filling period in severe left ventricular disease. Br Heart $₹$ 1989;62:246-52.

24 Klein AL, Tajik AJ. Doppler assessment of pulmonary venous flow in healthy subjects and in patients with heart disease. 7 Am Soc Echocardiogr 1991;4:379-92.

25 Keren G, Sonnenblick EH, LeJemtel TH. Mitral annulus motion: relation to pulmonary venous and transmitral flows in normal subjects and in patients with dilated cardiomyopathy. Circulation 1988;78:621-9.

26 Hoit BD, Shao Y, Tsai LM, Patel R, Gabel M, Walsh RA. Altered left atrial compliance after atrial appendectomy:
influence on left atrial and ventricular filling. Circ Res influence on left
$1993 ; 72: 167-75$.

27 Castello R, Pearson AC, Lenzen PM, Labovitz AL. Effect of mitral regurgitation on pulmonary venous velocities
derived from transesophageal echocardiography colorderived from transesophageal echocardiography colorguided pulsed

28 Keren G, Sherez J, Megidish R, Levitt B, Laniado S. Pulmonary venous flow pattern -its relationship to cardiac dynamics: a pulsed Doppler echocardiographic study. Circulation 1985;71:1105-12.

29 Masuyama T, Lee JM, Tamai M, Tanouchi J, Kitabatake A, Kamada $T$. Pulmonary venous flow velocity pattern as assessed with transthoracic pulsed Doppler echocardiography in subjects with

30 Appleton CP, Hatle LK, Popp RL. Relation of transmitral flow velocity patterns to left ventricular diastolic function: new insights from a combined hemodynamic and Doppler
echocardiographic study. $¥ \mathrm{Am}$ Coll Cardiol 1988;12: 426-40.

31 Matsuda Y, Toma Y, Matsuzaki M, Moritani K, Satoh A, Shiomi $\mathrm{K}$, et al. Change of left atrial systolic pressure waveform in relation to left ventricular end-diastolic pressure. Circulation 1990;82:1659-67.

32 Rossvoll O, Hatle LK. Pulmonary venous flow velocities recorded by transthoracic Doppler ultrasound: relation to left ventricular diastolic pressures. $₹ \mathrm{Am}$ Coll Cardiol 1993;21:1687-96.

33 Nishimura RA, Abel MD, Hatle LK, Holmes DR, Jr., Housmans PR, Ritman EL, et al. Significance of Doppler indices of diastolic filling of the left ventricle: comparison indices of diastolic filling of the left ventricle: comparison
with invasive hemodynamics in a canine model. $A m$ Heart $\mathcal{f}$ with invasive hemod

34 Masuyama T, St. Goar FG, Alderman EL, Popp RL. Effects of nitroprusside on transmitral flow velocity patterns in extreme heart failure: a combined hemodynamic and Doppler echocardiographic study of varying
ditions. $7 \mathrm{Am}$ Coll Cardiol 1990;16:1175-85.

35 Appleton CP. Influence of incremental changes in heart rate on mitral flow velocity: assessment in lightly sedated, conscious dogs. $\mathcal{F}$ Am Coll Cardiol 1991;17:227-36.

36 Klein AL, Burstow DJ, Tajik AJ, Zachariah PK, Bailey KR, Seward JB. Effects of age on left ventricular dimensions Proc 1994;69:212-24.

37 Miyatake K, Okamoto M, Kinoshita N, Owa M, Nakasone I, Sakakibara $\mathrm{H}$, et al. Augmentation of atrial contribution to left ventricular inflow with aging as assessed by intracardiac Doppler flowmetry. Am $\mathcal{f}$ Cardiol 1984;53:586-9.

38 Yamamoto K, Masuyama T, Tanouchi J, Doi Y, Kondo H, Hori $M$, et al. Effects of heart rate on left ventricular filling dynamics: assessment from simultaneous recordings of pulsed Doppler transmitral flow velocity pattern and haemodynamic variables. Cardiovasc Res 1993;27:935-41.

39 Yamamoto K, Masuyama T, Tanouchi J, Uematsu M, Doi $\mathrm{Y}$, Naito $\mathrm{J}$, et al. Importance of left ventricular minimal pressure as a determinant of transmitral flow velocity pat-
tern in the presence of left ventricular systolic dysfunction. f Am Coll Cardiol 1993;21:662-72.

40 Kitabatake $A$, Inoue $M$, Asao $M$, Tanouchi J, Masuyama T, Abe $\mathrm{H}$, et al. Transmitral blood flow reflecting diastolic behavior of the left ventricle in healthy and disease; a study by pulsed Doppler technique. Fpn Circ f 1982;46:92-102.

$41 \mathrm{Ng} \mathrm{KSK}$, Gibson DG. Relation of filling pattern to diastolic function in severe left ventricular disease. $\mathrm{Br}$ Heart $\mathcal{f}$ 1990;63:209-14.

42 Nishimura RA, Schwartz RS, Holmes DR, Jr., Tajik AJ. Failure of calcium channel blockers to improve ventricular relaxation in humans. 7 Am Coll Cardiol 1993;21:182-8.

43 Nishimura RA, Abel MD, Hatle LK, Tajik AJ. Relation of pulmonary vein to mitral flow velocities by transpulmonary vein to mitral flow velocities by transloading conditions. Circulation 1990;81:1488-97.

44 Appleton CP, Galloway JM, Gonzalez MS, Gaballa M, Basnight MA. Estimation of left ventricular filling pressures using two-dimensional and Doppler echocardiography in adult patients with cardiac disease. Additional value of analyzing left atrial size, left atrial ejection fraction and the difference in duration of pulmonary venous and mitral flow velocity at atrial contraction. $\mathcal{F}$ Am Coll Cardiol 1993; 22:1972-82.

45 Appleton CP, Hatle LK. The natural history of left ventricular filling abnormalities: assessment by two-dimensional and Doppler echocardiography. Echocardiography 1992;9: 437-57.

46 Klein AL, Hatle LK, Taliercio CP, Taylor CL, Kyle RA, Bailey KR, et al. Serial Doppler echocardiographic followdosis. F Am Coll Cardiol 1990;16:1135-41.

47 Xie GY, Berk MR, Smith MD, Gurley JC, DeMaria AN. Prognostic value of Doppler transmitral flow patterns in patients with congestive heart failure. $7 \mathrm{Am}$ Coll Cardiol 1994;24:132-9.

48 Rihal CS, Nishimura RA, Hatle LK, Bailey KR, Tajik AJ. Systolic and diastolic dysfunction in patients with clinical diagnosis of dilated cardiomyopathy. Relation to symptoms and prognosis. Circulation 1994;90:2772-9.

49 Dumesnil JG, Gaudreault G, Honos GN, Kingma JG, Jr. Use of Valsalva maneuver to unmask left ventricular diastolic function abnormalities by Doppler echocardiography in patients with coronary artery disease or systemic hyperin patients with coronary artery disease

50 Masuyama T, Kodama K, Kitabatake A, Sato H, Nanto S, Inoue $M$. Continuous-wave Doppler echocardiographic Inoue $M$. Continuous-wave Doppler echocardiographic detection of pulmonary regurgitation and its application to
noninvasive estimation of pulmonary artery pressure. noninvasive estimation of

51 Brun P, Tribouilloy C, Duval AM, Iserin L, Meguira A, Pelle G, et al. Left ventricular flow propagation during early filling is related to wall relaxation: a color $M$-mode Doppler analysis. $F$ Am Coll Cardiol 1992;20:420-32.

52 Yamamoto K, Masuyama T, Tanouchi J, Naito J, Mano T, Kondo $\mathrm{H}$, et al. Intraventricular dispersion of early diastolic filling: a new marker of left ventricular diastolic dysfunction. Am Heart $\mathcal{F}$ 1995;129:291-9.

53 Nishimura RA, Schwartz RS, Tajik AJ, Holmes DR, Jr. Noninvasive measurement of rate of left ventricular relaxation by Doppler echocardiography. Validation with simultaneous cardiac catheterization. Circulation 1993;88: $146-55$.

54 Yamamoto K, Masuyama T, Doi Y, Naito J, Mano T, Kondo $\mathrm{H}$, et al. Noninvasive assessment of left ventricular relaxation using continuous-wave Doppler aortic regurgitant velocity curve. Its comparative value to the mitral regurgitation method. Circulation 1995;91: 192-200.

55 Giannuzzi P, Imparato A, Temporelli PL, de Vito F, Silva PL, Scapellato F, et al. Doppler-derived mitral deceleration time of early filling as a strong predictor of pulmonary capillary wedge pressure in postinfarction patients with left ventricular systolic dysfunction. $\mathcal{F} \mathrm{Am}$ Coll Cardiol 1994; 23:1630-7.

56 Himura Y, Kumada T, Kambayashi M, Hayashida W, Ishikawa N, Nakamura Y, et al. Importance of left ventricIshikawa N, Nakamura Y, et al. Importance of left ventricdiastolic function with Doppler transmitral flow velocity decording. $7 \mathrm{Am}$ Coll Cardiol 1991;18:753-60.

57 Kuecherer HF, Muhiudeen IA, Kusumoto FM, Lee E, Moulinier LE, Cahalan MK, et al. Estimation of mean left atrial pressure from transesophageal pulsed Doppler echocardiography of pulmonary venous flow. Circulation 1990;82:1127-39.

58 Masuyama T, Lee JM, Nagano R, Nariyama K, Yamamoto $\mathrm{K}$, Naito J, et al. Doppler echocardiographic pulmonary venous flow-velocity pattern for assessment of the hemodynamic profile in acute congestive heart failure. Am Heart f 1995;129:107-13.

59 Yamamoto K, Nishimura RA, Higano ST, Redfield MM. The accuracy of Doppler analysis of left ventricular filling pressure is dependent upon the degree of left ventricular systolic dysfunction (abstract). Circulation 1995;92:I-397.

60 Klein AL Hatle LK, Taliercio CP, Oh JK, Kyle RA Gert $\mathrm{MA}$, et al. Prognostic significance of Doppler measures of diastolic function in cardiac amyloidosis. A Doppler echocardiography study. Circulation 1991;83:808-16.

61 Nagano R, Masuyama T, Lee JM, Yamamoto K, Naito J, Mano T, et al. Transthoracic Doppler assessment of pattern of left ventricular dysfunction in hypertensive heart disease: combined analysis of mitral and pulmonary venous flow velocity patterns. $\mathcal{f}$ Am Soc Echocardiogr 1994;7:493-505. 